\title{
Quantification of Carbonaceous Aerosol Emissions from Cookstoves in Senegal
}

\author{
Candela de la Sota ${ }^{*}$, Mar Viana ${ }^{2}$, Moustapha Kane ${ }^{3}$, Issakha Youm ${ }^{3}$, Omar Masera $^{4}$, \\ Julio Lumbreras ${ }^{1}$
}

\author{
${ }^{1}$ Department of Chemical and Environmental Engineering, School of Industrial Engineering, Technical University of \\ Madrid, 28006 Madrid, Spain \\ ${ }^{2}$ Institute of Environmental Assessment and Water Research, Spanish National Research Council (IDAEA-CSIC), 08034 \\ Barcelona, Spain \\ ${ }^{3}$ Centre for Studies and Research on Renewable Energy (CERER) of the Cheikh Anta Diop University of Dakar (UCAD), \\ 476 Dakar, Senegal \\ ${ }^{4}$ Institute for Ecosystems and Sustainability Research, National Autonomous University of Mexico, 58190 Morelia, \\ Michoacán, México
}

\begin{abstract}
In some regions of the world, cooking with solid biomass fuels in open fires constitutes the largest source of elemental and organic carbon emissions. However, cooking-related carbonaceous aerosols are still poorly characterized. This paper presents an innovative characterization of elemental and organic carbon (EC and OC) emissions from cookstoves in West Africa. Four stove types (three-stone fire, rocket stove, basic ceramic stove, and gasifier) using two wood species (dimb and filao) were analyzed on a laboratory scale. The EC and OC emission factors based on fuel energy (EFs) when burning dimb were higher for all stoves, highlighting the need to account for the fuel type when reporting cookstove EFs. The highest EC EF was found for the rocket stove $\left(0.18 \pm 0.06 \mathrm{~g} \mathrm{MJ}^{-1}\right.$ and $0.06 \pm 0.01 \mathrm{~g} \mathrm{MJ}^{-1}$ for dimb and filao, respectively). The other tested stoves exhibited the same EC EF when burning dimb $\left(0.09 \pm 0.02 \mathrm{~g} \mathrm{MJ}^{-1}\right)$ and EC EFs ranging between $0.04 \pm 0.01$ and $0.05 \pm 0.01 \mathrm{~g} \mathrm{MJ}^{-1}$ when burning filao. The OC EF was highest, on average, for the gasifier $(0.08 \pm$ $\left.0.01 \mathrm{~g} \mathrm{MJ}^{-1}\right)$, followed by those for the three-stone fire $\left(0.18 \pm 0.03 \mathrm{~g} \mathrm{MJ}^{-1}\right)$ and the basic ceramic stove $\left(0.21 \pm 0.08 \mathrm{~g} \mathrm{MJ}^{-1}\right)$. However, the results from testing the rocket stove and the three-stone fire under real cooking conditions using dimb wood indicate that the laboratory-scale tests overestimate the actual EC EFs. Also, the rocket stove did not show a reduction in wood use compared to the three-stone fire, suggesting that the carbonaceous aerosol emissions from the former produce more warming than those from the latter. Therefore, the total EC and OC stove emissions, in addition to the EFs, must be reported. As the impacts of carbonaceous aerosol highly depend on the location of emission, this study contributes valuable data to emission inventories and climate prediction models at national and regional levels.
\end{abstract}

Keywords: Emission factor; Rocket stove; Traditional stove; West Africa.

\section{INTRODUCTION}

In Senegal, $83 \%$ percent of households, mainly in rural villages, depend on biomass fuels to cover their daily cooking energy needs (World Bank, 2013). Combustion of these fuels is usually performed with inefficient stoves, leading to high levels of indoor air pollution and causing the premature death of 6300 people every year, mainly women and children (WHO, 2009).

Moreover, cookstove emissions contribute to ambient

\footnotetext{
* Corresponding author.

Tel.: +34 699284386

E-mail address: candela.delasota@upm.es
}

air pollution and have relevant effects on climate change (Bond, 2004; Venkataraman et al., 2005; Chafe et al., 2014). The carbonaceous components of particulate matter (organic and elemental carbon) emitted during incomplete combustion of biofuels has a strong bearing on the atmospheric radiative balance (Arora and Jain, 2015).

Elemental carbon (EC) (or black carbon (BC)) content of particulate matter (PM) has been identified as having the second highest warming impact, despite its short residence time in the atmosphere (Jacobson, 2001). BC refers to the light-absorbing carbon, measured by change in light transmittance or reflection, whereas EC is measured by thermal evolution under high-temperature oxidation (Venkataraman et al., 2005). Even though EC and BC are not exactly equivalent (Salako, 2012; Petzold et al., 2013), both terms are often used interchangeably (Chen et al., 
2005; Venkataraman et al., 2005; Bond and Bergstrom, 2006; Li et al., 2009; Shen et al., 2010).

The other major carbonaceous aerosol component, organic carbon (OC), has been linked to light scattering properties (Chung and Seinfeld, 2002), although OC from biofuel combustion has been shown to be slightly absorbing due to the presence of brown carbon (Bond et al., 2007; Feng et al., 2013).

Aerosols from biomass burning also cause alterations in the environmental conditions at regional and local levels, like visibility reductions and changes in rainfall patterns, which can be substantially large (Ramanathan and Carmichael, 2008). In regions where residential biofuel combustion is prevalent over other energy sources, like sub-Saharan Africa, Asia and South America, the residential sector is the dominant contributor to BC emissions (Bond, 2004) and worldwide, approximately $25 \%$ of $\mathrm{BC}$ (although with large uncertainty) and $20 \%$ of OC emissions comes from residential burning of biomass fuels (Bond, 2004; Lamarque et al., 2010).

However, cooking-related aerosols are much less studied than those of other common sources (Roden et al., 2006; Soneja et al., 2015) like diesel engines, leading to an important underestimation of climate impacts from traditional burning of biomass at residential level (Grieshop et al., 2011; Lee and Chandler, 2013).

The complexity of studies of aerosol emissions from cooking is related to the wide distribution and remote location of the sources (Johnson et al., 2008), the complicated effect of OC (Feng et al., 2013), the relatively complex BC and OC measurement methods (Ramanathan et al., 2011; de la Sota et al., 2017) and because EC and OC emissions range widely between different cooking technologies and biofuels (Venkataraman et al., 2005; MacCarty et al., 2008; Grieshop et al., 2011; Shen et al., 2012).

Some studies that estimate the EC and OC EFs from cooking technologies are available for the Asian region (Zhang et al., 2000; Venkataraman et al., 2005; Li et al., 2009; Shen et al., 2010; Chen et al., 2012; Shen 2012, 2013; Arora and Jain, 2015); and some contributions have been made from Latin America (Roden et al., 2006; Johnson et al., 2008; Roden et al., 2009). However, only one study has been performed in sub-Saharan Africa (Malawi) (Wathore et al., 2017) and, to the best of our knowledge, there are no studies regarding the characterization of aerosol emissions from cooking in the West African region.

This paper presents a laboratory scale characterization of aerosol emissions from four stove-fuel combinations widely used in Senegal and other West African countries. Two of these stove-fuel combinations were tested in addition in a rural village of Senegal to understand how real cooking practices in this region influence $\mathrm{EC}$ and $\mathrm{OC}$ emissions. Finally, total EC and OC emissions and the net climate effect from fuelwood burning at household level in Senegal and West Africa were estimated.

A better knowledge of aerosol emissions from residential biofuels in West Africa should contribute to reduce the uncertainties on emission inventories and climate prediction models at regional level, and should result in a more representative and robust estimation of the climatic impacts of this source.

Moreover, this information should help improve cookstove initiatives to be considered within the national and regional short-lived climate pollutant reduction strategies, for addressing both near-term and long-term climate change impact, as well as health and social benefits (Shoemaker et al., 2013).

\section{METHODS}

\section{Laboratory Sampling}

Laboratory tests were conducted at the Centre de Études et Recherches sur les Énergies Renouvelables (CERER) of the University of Dakar, using a Laboratory Emissions Monitoring System (LEMS), developed by Aprovecho Research Center (ARC) (MacCarty et al., 2010). $\mathrm{PM}_{2.5}$ samples were collected via two parallel filters (diameter: $102 \mathrm{~mm}$ ), one running at $3 \mathrm{~L} \mathrm{~min}^{-1}$ with quartz-fiber filters (Pallflex Tissuquartz, 2500 QAT-UP; Pall Corporation) for OC-EC analyses, and the other running at $16.7 \mathrm{~min}^{-1}$ with glass fiber filters (FPAE-102, Hi-Q Environmental Products) for gravimetric $\mathrm{PM}_{2.5}$ measurements. No backup filters were used for quantification of sampling artefacts (Turpin et al., 2000).

Three replicates of the Water Boiling Test (WBT) (Bailis et al., 2007) were conducted to test each cooking system. In this standard measurement, 5 liters of water were brought to a boil (cold start phase) and then simmered for 45 minutes. Although the WBT includes three phases (cold start, hot start and simmer), in this study only the cold start and simmer phases were included, to maximize the available resources (time and funds). This simplification can be made when previous WBTs have shown that the cold-start and hot-start phases produce similar results (EPA et al., 2014).

The WBT has recognized limitations to reproduce actual random conditions in the field (Roden et al., 2006; Johnson et al., 2008; Shen et al., 2013). However, its repeatability allows the study of the effect of design on the performance of cookstoves, as well as the emission process influencing factors, mechanisms and kinetics (Chen et al., 2012; Shen et al., 2013; Arora and Jain, 2015).

\section{Field Sampling}

In-home tests were conducted in March 2016 in Bibane, a rural village in the region of Fatick (Senegal). Emissions testing was done using a Portable Emission Monitoring System (PEMS, ARC), with a similar design as the LEMS, but with a portable hood made from fireproof fabric. The portable hood was placed before starting the meal preparation directly over the center of the combustion zone (see Fig. S1) allowing cookers to have an acceptable space for the stove use. Background concentrations were sampled and then subtracted from the emission sample concentrations.

Emission sampling started once the fire was lit, the start time was recorded, and cooks placed the pot on the stove a few seconds after the ignition. At the end of the food 
preparation stage, emissions sampling was terminated, cooked food weighed, and end time recorded. Fuelwood was measured before and after cooking sessions, as well as the charcoal formed. Our goal was to minimize interference with normal cooking practices, so the food prepared during the tests was freely chosen by families.

The PEMS was connected to a diesel generator, placed far enough away to not disturb women while cooking and to avoid emissions interferences.

\section{Stoves and Fuels}

Four stoves were selected in this study between the most commonly used in rural Senegal, each one representing a method of fuelwood combustion: i) three-stone fire (open burning traditional stove); ii) noflaye jegg (rocket combustion chamber-type locally produced); iii) jambaar bois (basic improved ceramic stove, widely distributed in the Dakar region by the German cooperation PERACOD program); iv) prime square stove (a top-lit updraft gasifier, TLUD, with a natural draft, with no fan). Photos of the stoves are shown in Fig. S2.

Each stove was tested in the laboratory using two wood species: Casuarina equisetifolia (commonly named filao) and Cordyla pinnata (commonly named $\operatorname{dimb}$ ). Both were split in regular pieces of $15 \times 5 \times 3 \mathrm{~cm}$ (approximately). Moisture content on a wet basis for dimb and filao was $8 \%$ and $8.8 \%$, respectively, and calorific value was $21.69 \mathrm{MJ} \mathrm{kg}^{-1}$ and $19.0 \mathrm{MJ} \mathrm{kg}^{-1}$, respectively. Three stones and noflaye jegg (rocket design) were the stove types analyzed in the field. The three-stone fire is still the most commonly used biomass stove in Senegal, and noflaye jegg stove has been widely implemented in Senegal and neighboring countries (Sota et al., 2014).

In 2012, within the framework of a program to optimize the use of forest resources in the region, 50 noflaye jegg stoves were distributed in Bibane. However, only 15 out of 50 stoves were in good or fair state, and considered adequate to be included in the study and some of them needed minor repairs before starting the tests. Finally, 15 households with improved cookstoves were included in the study, together with another 14 using the traditional three stone fire.

As fuel used in Bibane was quite heterogeneous due to fuelwood scarcity, the same wood was distributed to every family participating in the study. Testing with uniform wood type allowed us to reduce the variability between households and to focus the study on the effect of stove type on carbonaceous aerosol emissions. Wood used during field testing (dimb) was purchased from a local vendor, bigger and more irregular pieces than those used in the laboratory, and distributed to households. Purchased dimb had a moisture content of $5 \%$ on a wet basis and a calorific value for dry fuel of $21.69 \mathrm{MJ} \mathrm{kg}^{-1}$.

\section{EC and $O C$ Analysis}

After sampling, particle-loaded filters were packed with aluminum foil and stored in a freezer until analysis. Gravimetric measurements of glass fiber filters were conducted using a high precision digital balance at the
CERER, and OC/EC analyses on quartz filters were conducted with a Sunset Laboratory carbon analyzer using the EUSAAR 2 Protocol (Cavalli et al., 2010), in the Institute of Environmental Assessment and Water Research IDAEA-CSIC in Barcelona. This protocol has been already used in cookstove aerosol emission analysis (de la Sota et al., 2017).

\section{Data Analysis}

Kruskal-Wallis one-way analysis of variance was used to identify significant differences of OC and EC EFs with different cookstoves, fuels and during different WBT phase. Wilcoxon $t$-test was conducted in order to identify pairs with statistically significant difference in EF values. Non parametric tests were used because observations were not normally distributed, due to the relative small sample size and the presence of outliers (mainly in results from the field study).

The interquartile range (IQR), difference between the $75^{\text {th }}$ percentile and the $25^{\text {th }}$ percentile, was used to determine the test-to-test variability. This measure is robust against outliers and non-normal data. All statistical analyses were conducted at a significance level of 0.05 and performed using IBM SPSS Statistics Base software.

\section{RESULTS AND DISCUSSION}

\section{Laboratory Estimation of EC and $O C$ Emission Using the $W B T$}

Fig. 1 presents EC EFs (in grams per MJ fuel energy, for comparison on the same scale), total fuel consumption per WBT and EC total emissions per WBT completed (cold start + simmer).

Results on Fig. 1(a) show that the type of stove had an effect on EC EFs. The highest average EC EF per WBT was found with the noflaye jegg for both fuels (dimb and filao), while EC EFs were fairly uniform across the other two improved cookstoves and the three-stone fire.

Differences of EC EFs between stoves are related to the nature of combustion (MacCarty et al., 2007; Arora and Jain, 2015), which is, in turn, affected by a number of factors (e.g., air-fuel ratio, burn rate, combustion temperature, combustion efficiency, thermal efficiency, residence time in the combustion chamber, flame turbulence, etc.) (MacCarty et al., 2008; Venkataraman et al., 2005).

In this study, the $\mathrm{CO} / \mathrm{CO}_{2}$ ratio was used as a benchmark for stove combustion efficiency (Li et al., 2009; Shen et al., 2012). The noflaye jegg (rocket stove) performed with the lowest $\mathrm{CO} / \mathrm{CO}_{2}$ ratios $(3.4 \pm 1.1 \%$ for dimb and $5.3 \pm$ $0.1 \%$ for filao), indicating an acceptable efficient combustion (target value is $2 \%$ or less), and the highest EC EFs $(0.18 \pm$ $0.06 \mathrm{~g} \mathrm{MJ}^{-1}$ and $0.06 \pm 0.01 \mathrm{~g} \mathrm{MJ}^{-1}$ ) for dimb and filao, respectively.

Rocket stoves have a strong draft which enhances air flow through the fire, improving the combustion efficiency and resulting in higher combustion temperatures (MacCarty et al., 2008; Li et al., 2009), which typically results in higher EC emissions (Rau, 1989; Cachier et al., 1996; Bond, 2004; MacCarty et al., 2008). 

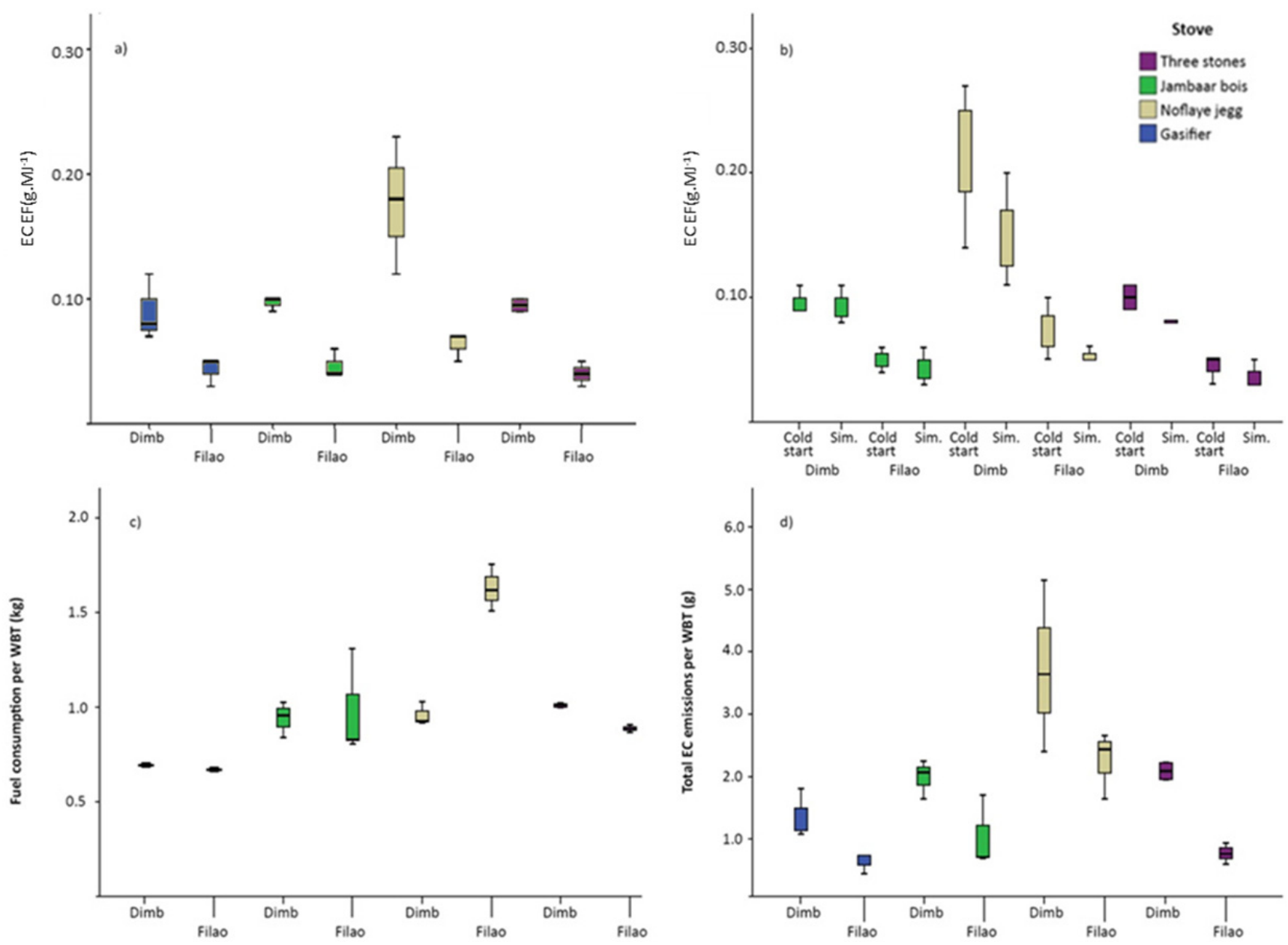

Fig. 1. Laboratory estimation of EC emission using the WBT. (a) EC EFs per MJ fuel energy for the WBT; (b) EC EFs per MJ fuel energy for each WBT phase (cold-start and simmer); (c) Fuel consumption per WBT; (d) Total EC Emissions per WBT.

The three-stone fire showed the highest $\mathrm{CO} / \mathrm{CO}_{2}$ ratios $(8.7 \pm 0.5 \%$ with dimb and $8.3 \pm 1.8 \%$ with filao), indicating inefficient combustion, and low values of EC EF (0.09 \pm $0.01 \mathrm{~g} \mathrm{MJ}^{-1}$ for dimb and $0.04 \pm 0.01 \mathrm{~g} \mathrm{MJ}^{-1}$ for filao).

Jambaar bois showed very similar values to the threestone fire, both in combustion efficiency and EC EF values. $\mathrm{CO} / \mathrm{CO}_{2}$ ratio was $7.8 \pm 2.4 \%$ and $6.7 \pm 1.9 \%$; and $\mathrm{EC} \mathrm{EFs}$ were $0.09 \pm 0.01 \mathrm{~g} \mathrm{MJ}^{-1}$ and $0.05 \pm 0.01 \mathrm{~g} \mathrm{MJ}^{-1}$, with dimb and filao, respectively. Previous studies have also found EFs for basic ceramic stoves similar to traditional stoves (Wathore et al., 2017).

The gasifier showed $\mathrm{CO} / \mathrm{CO}_{2}$ ratio of $3.6 \pm 0.6 \%$ and $4.0 \pm$ $0.4 \%$, with dimb and filao, respectively (i.e., high combustion efficiency), and low EC EFs: $0.09 \pm 0.02 \mathrm{~g} \mathrm{MJ}^{-1}$ when burning dimb (equal to EF of jambaar bois and three-stone fire) and $0.05 \pm 0.01 \mathrm{~g} \mathrm{MJ}^{-1}$ with filao. This is coherent with previous findings showing the lowest EF for gasifiers in comparison with traditional and other basic improved stoves (MacCarty et al., 2008; Arora and Jain, 2015; Wathore et al., 2017) (Table S1).

In addition to the cookstove technology, the biofuel characteristics also determine combustion conditions, and thus, aerosol emissions (Venkataraman and Rao, 2001;
Venkataraman et al., 2005; Li et al., 2009). In our study, EC EFs of all the stoves tested showed higher values when burning dimb over filao $(64.2 \%, 51.7 \%, 49.7 \%$ and $56.7 \%$ for the noflaye jegg, jambaar bois, gasifier and three-stone fire, respectively), although not statistically significant $(p>0.05)$.

A number of characteristics of fuelwood could affect pollutant emissions: i) the geometrical shape and size of the fuel; ii) the density (Atiku et al., 2016; Mitchell et al., 2016); iii) the lignin content (Atiku et al., 2016); iv) the heat value and v) the moisture (Chomanee, 2009; Shen et al., 2010), among others.

Dimb and filao used in this study had similar moisture fraction, calorific value and size. Typical lignin content is around 26\% for filao (Mahmood, 1993), and 40\% for dimb (Samba, 2001). Previous studies show that lignin content promotes elemental carbon formation (Tillman, 1987; Atiku et al., 2016), so this may partially explain the higher EC EFs of dimb wood.

Results suggest that emission factors of EC are dependent on the type of fuel burned, but further studies could examine the effect of physical and chemical characteristics of filao and dimb in EC EFs, which cannot be explained at this stage. 
Fig. 1(b) presents EC EFs for the stove-fuel combinations by WBT phase, except in the case of the gasifier, where only the EF of the whole WBT is presented, because its cylindrical combustion chamber cannot be emptied during the burning cycle. EC EFs were found to be higher during the cold start phase for every stove-fuel combination analyzed. This can be explained because cold start phase is characterized by strong flames and significant amounts of elemental carbon (Roden et al., 2009; Atiku et al., 2016), especially shortly after fire ignition (Roden et al., 2006), whereas the simmer phase is characterized by smaller flames, with lower emission of EC particles (Roden et al., 2006).

EC EFs were $20 \%, 10 \%$ and $29 \%$ higher for the cold start phase with regard to simmer, for the dimb with threestone fire, jambaar bois and noflaye jegg, respectively; and $25 \%, 20 \%$ and $14 \%$ higher for filao with three-stone fire, jambaar bois and noflaye jegg, respectively; though not statistically significant $(\mathrm{p}>0.05)$. Previous studies also found that changes in combustion conditions during the cooking cycle induced variation in EC EFs (Roden et al., 2006; Jetter et al., 2012; Arora and Jain, 2015).

In terms of total EC emission per WBT completed, Fig. 1(d) shows that results followed almost the same trend as in the case of average EC EFs per WBT. Noflaye jegg showed the highest EC EF and did not show a reduction in fuelwood consumption per task completed with respect to the three-stone fire (Fig. 1(c)). Therefore, this type of stove has the highest EC emissions per WBT (3.75 g per WBT with dimb and $1.90 \mathrm{~g}$ per WBT with filao). On the other hand, the gasifier showed the highest fuel savings and low EC EFs, so this type of stove achieved the smallest total EC emissions per WBT (1.35 g per WBT with dimb and $0.57 \mathrm{~g}$ per WBT with filao). An intermediate situation was found for the three-stone fire and the jambaar bois, which show very similar results in terms of EC total emissions (three-stone fire, $2.00 \mathrm{~g}$ per WBT with dimb and $0.67 \mathrm{~g}$ per WBT with filao) and jambaar bois (1.94 g per WBT with dimb and $0.89 \mathrm{~g}$ per WBT with filao). The fuel consumption value obtained for the noflaye jegg with filao (and, therefore, the value of total emissions) in this study should be considered with caution, since in the other stove types tested, fuelwood consumption used does not vary with the species used.

Fig. 2 presents OC EFs for the three-stone fire, jambaar bois, and gasifier, when burning filao. OC EFs for the rest of stove-fuel combinations are not presented due to problems in filter handling between WBT and EC/OC analysis.

When burning filao wood, the average OC EF for the whole WBT was found to be the lowest for the gasifier $\left(0.08 \pm 0.01 \mathrm{~g} \mathrm{MJ}^{-1}\right)$, followed by three-stone fire $(0.18 \pm$ $\left.0.03 \mathrm{~g} \mathrm{MJ}^{-1}\right)$ and then jambaar bois $\left(0.21 \pm 0.08 \mathrm{~g} \mathrm{MJ}^{-1}\right)$. Low OC and EC emissions of gasifier are explained because this technology emits very low levels of particulate matter when compared to other biomass stoves (MacCarty et al., 2008). As already observed in previous studies, in the case of the three-stone fire and jambaar bois, a large bed of charcoal under the flaming fuel resulted in smoldering conditions, with high OC particles emissions (MacCarty et al., 2007). Overall, our OC EF results appear to be consistent with prior studies (Table S1).

Test phases that were associated with higher OC emissions had different results depending on the cookstove tested, as occurred in previous studies (Arora and Jain, 2015). For the traditional stove, OC EF was found to be higher during simmer $\left(0.19 \pm 0.05 \mathrm{~g} \mathrm{MJ}^{-1}\right)$ than during cold start $\left(0.16 \pm 0.03 \mathrm{~g} \mathrm{MJ}^{-1}\right)$, whereas jambaar bois showed highest OC EF during cold start $\left(0.22 \pm 0.09 \mathrm{~g} \mathrm{MJ}^{-1}\right)$ when compared to simmer phase $\left(0.19 \pm 0.05 \mathrm{~g} \mathrm{MJ}^{-1}\right)$, although none of these differences between WBT phases were statistically significant (Wilcoxon, $\mathrm{p}<0.05$ ).

Akagi et al. (2011) attributed higher OC emissions during the simmer phase to high carbon content and large surface area per unit mass of charcoal that results in the formation of organic compounds. On the other hand, higher OC emissions during flaming conditions (cold start phase) with the jambaar bois, could be attributed to low flame temperatures due to heat losses through the cookstove walls (Arora and Jain, 2015).

Fig. 2(d) presents results of OC/EC ratio, considered an environmentally relevant property with good predictive capabilities in determining the impact of absorbing aerosol on the earth's radiative balance, even for fuels in which brown carbon absorption is significant (Pokhrel et al., 2016). Overall, all stove fuel combinations showed OC/EC ratios higher than one, indicating the dominance of $\mathrm{OC}$ and suggesting that the smoldering combustion was dominant during the WBT. However, real-time data such as the modified combustion efficiency (MCE), $\mathrm{CO}_{2} /\left(\mathrm{CO}+\mathrm{CO}_{2}\right)$, and single-scattering albedo would be better proxies to differentiate between smoldering and flaming dominated combustion.

Figs. 1 and 2 show a relatively large degree of test-totest variability (boxes overlapped considerably). For this reason, differences in OC and EC EFs across stove types, phases of WBT and types of fuel were not found to be statistically significant in most cases $(p>0.05)$.

In the laboratory evaluation of EC emissions using the WBT (Fig. 1), the highest test-to-test variability was observed with the noflaye jegg (interquartile range, IQR = 2.8 with dimb and IQR $=1.03$ with filao, Fig. $1(\mathrm{~d})$ ). This is because flaming conditions are more present in the cooking cycle for this stove, characterized by more frequent peaks of emissions, which significantly affect total EC. For OC emissions, jambaar bois showed the highest IQR, equal to 2.9 (Fig. 2(c)).

In this study three replicates of WBT were conducted because it was commonly used in the literature (Wang et al., 2014). However, number of replicates is linked to the stove-fuel combination being tested and sometimes three are not enough to ensure confidence in the results (Wang et al., 2014). Our findings suggest that in forthcoming emissions testing of the stoves included in this study, a larger number of WBT replicates, especially for the stoves with greater variation in performance, should be analyzed.

\section{Field Estimation of EC and OC Emission Factors}

Most families cooked inside the kitchen space during 

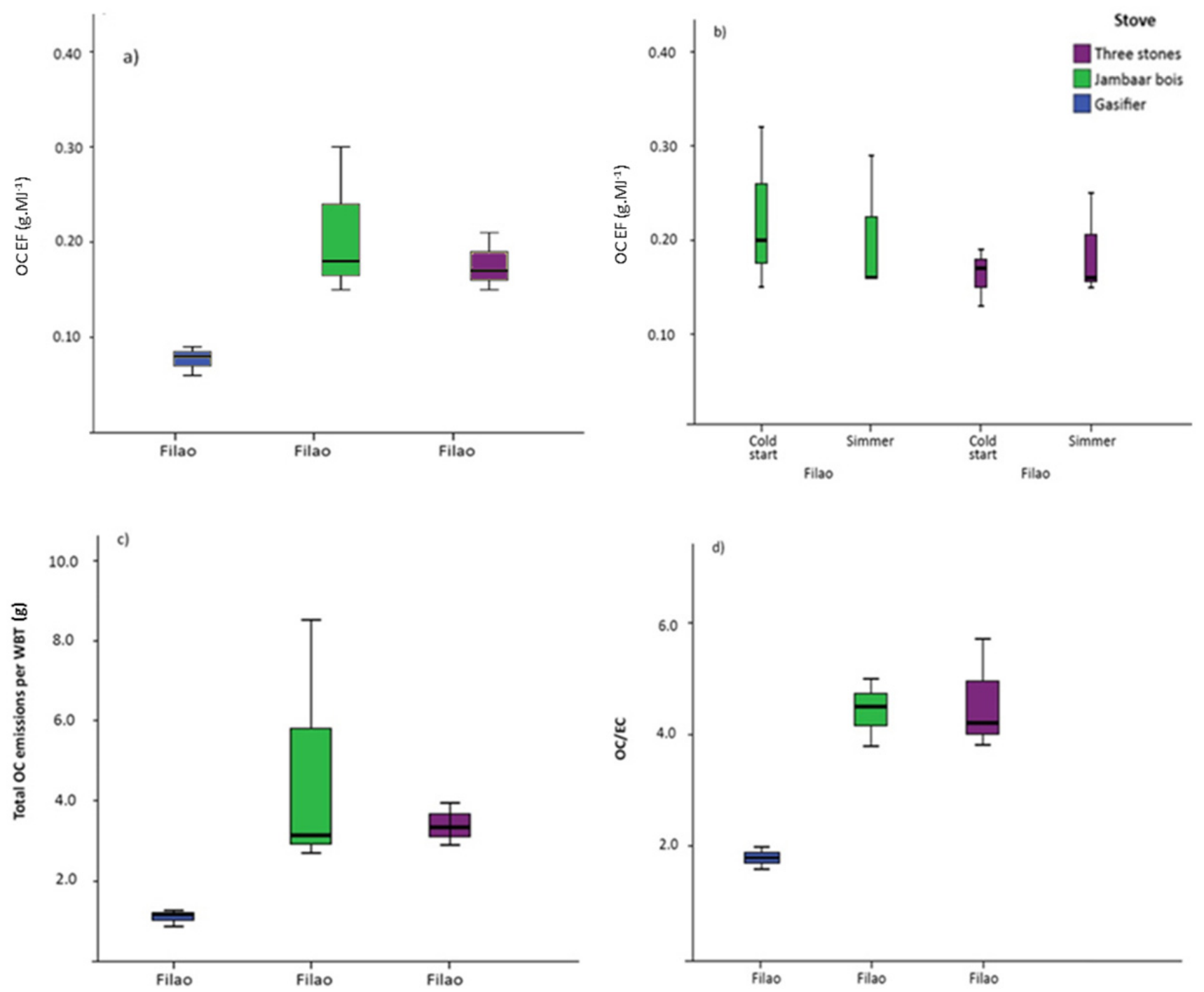

Fig. 2. Laboratory estimation of OC emission using the WBT. (a) OC EFs per MJ fuel energy for the WBT; (b) OC EFs per MJ fuel energy for each WBT phase (cold-start and simmer); (c) Total OC emissions per WBT; (d) OC/EC ratio.

the tests (separated from the rest of the house and very poorly ventilated), although a few of them cooked outdoors. They prepared typical meals of rural households in the region, that consisted of rice with vegetables, fish, or meat for lunch, whereas for dinner, water was boiled to steam couscous and a sauce was prepared. Time of preparation ranged from 38 to 111 minutes (average $=75$ minutes), with no significant differences between lunch and dinner and between the type of stove used. Likewise, no differences were found in the quantity of fuel used per $\mathrm{kg}$ of food prepared between the three-stone fire and the noflaye jegg ( $0.6 \mathrm{~kg}$ of fuel per $\mathrm{kg}$ of food), consistent with previous laboratory results in this study.

As fuelwood type was the same for every household, our field results focused on the analysis of the influence of stove type on EC and OC emissions. EC EFs (Fig. 3(a)), increased $75 \%(\mathrm{p}<0.05)$ with noflaye jegg in comparison with the three-stone fire stove. On the other hand, OC EFs (Fig. 3(b)) were 30.3\% and 35.7\% lower for noflaye jegg when compared to the three-stone fire, though not statistically significant $(\mathrm{p}>0.05)$. The ratio OC/EC (Fig. 3(c)) was $1.77 \pm 0.56$ for the three-stone fire, indicating the dominance of OC, which may be caused by the smoldering combustion (MacCarty et al., 2008). OC/EC ratio $<1(0.67 \pm 0.28)$ for the noflaye jegg is showing the dominance of EC produced by flaming conditions, typical in the rocket stoves (MacCarty et al., 2008).

Therefore, EC EFs are higher with the noflaye jegg and thus this stove may be more warming (from a climate perspective, considering only EC and OC) when compared to the three-stone fire, which could lessen some of the impact of reducing overall aerosol emissions (Johnson et al., 2008). However, the comparison of both stoves should be done in terms of total EC and OC emissions, taking into account their fuel-efficiency (see section "Estimation of total emissions and net climate effect of cooking-related carbonaceous aerosol in Senegal").

Overall, EC and OC EFs obtained agree well with previous studies (Table S1), although many differences were observed due to differences on stove type, fuel parameters, 

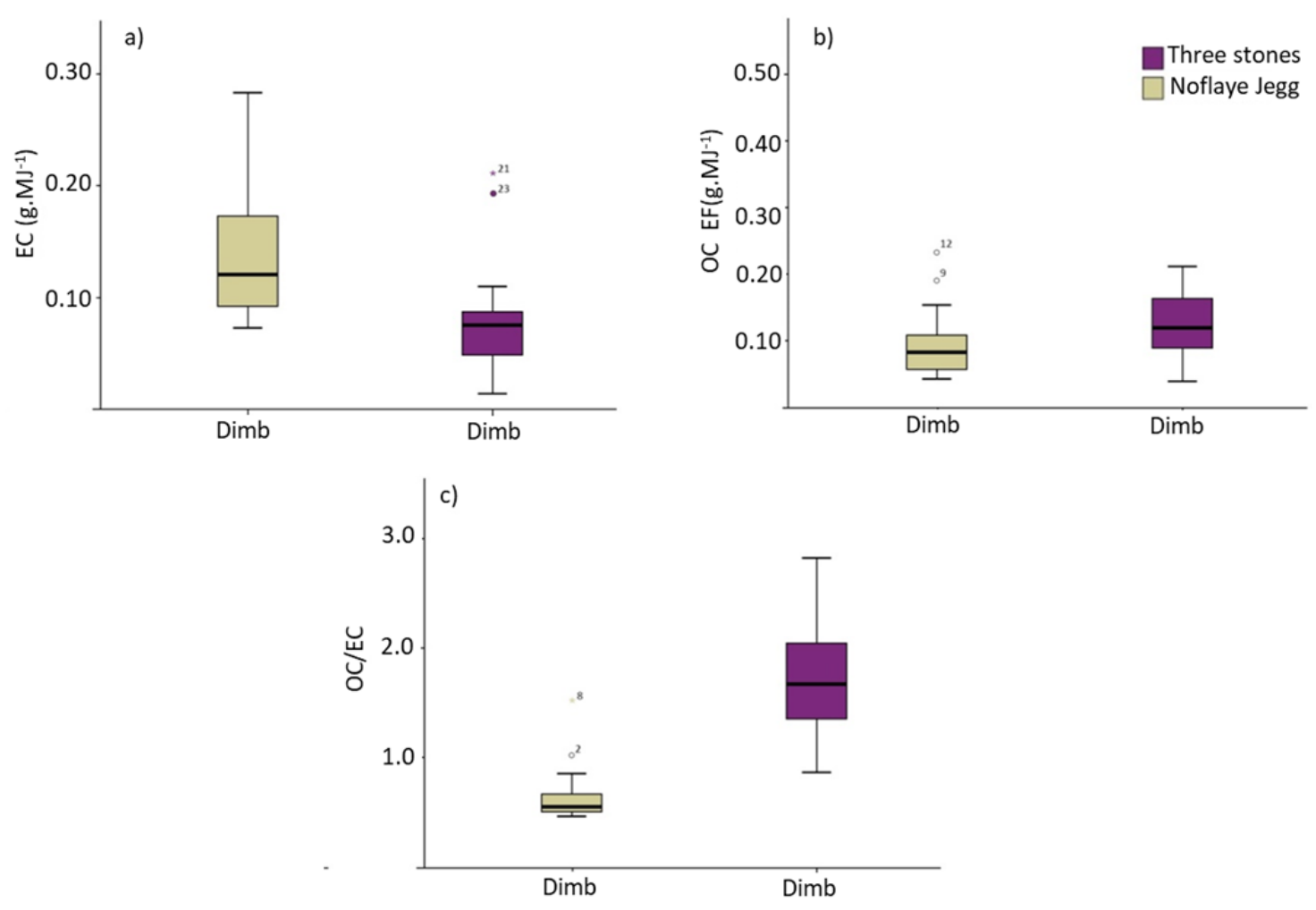

Fig. 3. Field estimation of EC and OC emissions. (a) EC EFs; (b) OC EFs; (c) OC/EC.

operation conditions, etc. Nonetheless, most publications present EF in $\mathrm{g} \mathrm{kg}^{-1}$ instead of $\mathrm{g} \mathrm{MJ}^{-1}$, which prevents comparison between different fuel types at same level.

\section{Laboratory vs. Field Results}

EC EFs from WBT were compared with results obtained under field conditions for the three-stone fire and the noflaye jegg stoves when burning dimb (Fig. 4).

EC EFs estimated at laboratory scale were $18.0 \%$ higher than during daily cooking activities for the noflaye jegg, and $14.5 \%$ higher in the case of the three-stone fire (not significant, $p>0.05$ ). These results suggest an overestimation of EC EFs at laboratory scale, when compared with field conditions. Previous studies also found differences between results from laboratory tests and those obtained during field conditions (Roden et al., 2006; Johnson et al., 2008; Roden et al., 2009; Chen et al., 2012; Shen et al., 2013; Arora and Jain, 2015), although differences were larger than in this study.

Differences between laboratory and field results can be explained by several factors. First, the fire management behavior in the laboratory was essentially normalized, the cooking fire was constantly tended and fuel was added frequently, whereas the process observed in the field was rather random, including some low combustion efficiency situations due to infrequent tending. Wood pieces used in the laboratory had regular shape and dimensions, while in the field they were less uniform in shape and with larger dimensions. Smaller wood has been found to yield lower $\mathrm{PM}$ emissions and a higher $\mathrm{BC}$ fraction of emissions (Bond, 2004; Li et al., 2009). Thirdly, stove age may affect the stove fuel consumption and emissions (Naeher et al., 2000). Finally, minor fugitive emissions may have escaped from the fabric hood during field testing.

Differences between lab and field EFs were lower during the simmer phase of WBT: $3.8 \%$ for the three-stone fire and $4.2 \%$ for the noflaye jegg $(\mathrm{p}>0.05)$ (see Table S4, supporting information).This is coherent with our field observations, which showed that during meal preparations, cooks maintained a constant and low-medium flame during almost all the time, except when frying for the first few minutes, which needed stronger flames.

Although user practices are highly individual, regional averages may be governed by common customs (Chen et al., 2012), simmer phase of WBT is likely quite illustrative of EC emissions in homes of rural villages of Senegal. Further field measurements are needed as a reality check for each stove-test and region.

\section{Estimation of Total Emissions and Net Climate Effect of Cooking-related Carbonaceous Aerosol in Senegal}

Total annual EC and OC emission per year of use of the noflaye jegg and the three-stone fire were calculated with EF values and data of daily consumption $\left(9.9 \pm 5.1 \mathrm{~kg} \mathrm{day}^{-1}\right.$ for the noflaye jegg and $9.6 \pm 5.5 \mathrm{~kg} \mathrm{day}^{-1}$ for the threestone fire), both determined during the field study. As in this region cooking activities occur most often in indoor environments, it was necessary to take into account the fraction of emissions released to ambient air (exfiltration rate), which is dependent on the ventilation and particle deposition rates in kitchens (Soneja et al., 2015). Exfiltration rate for typical household characteristics of this study was 


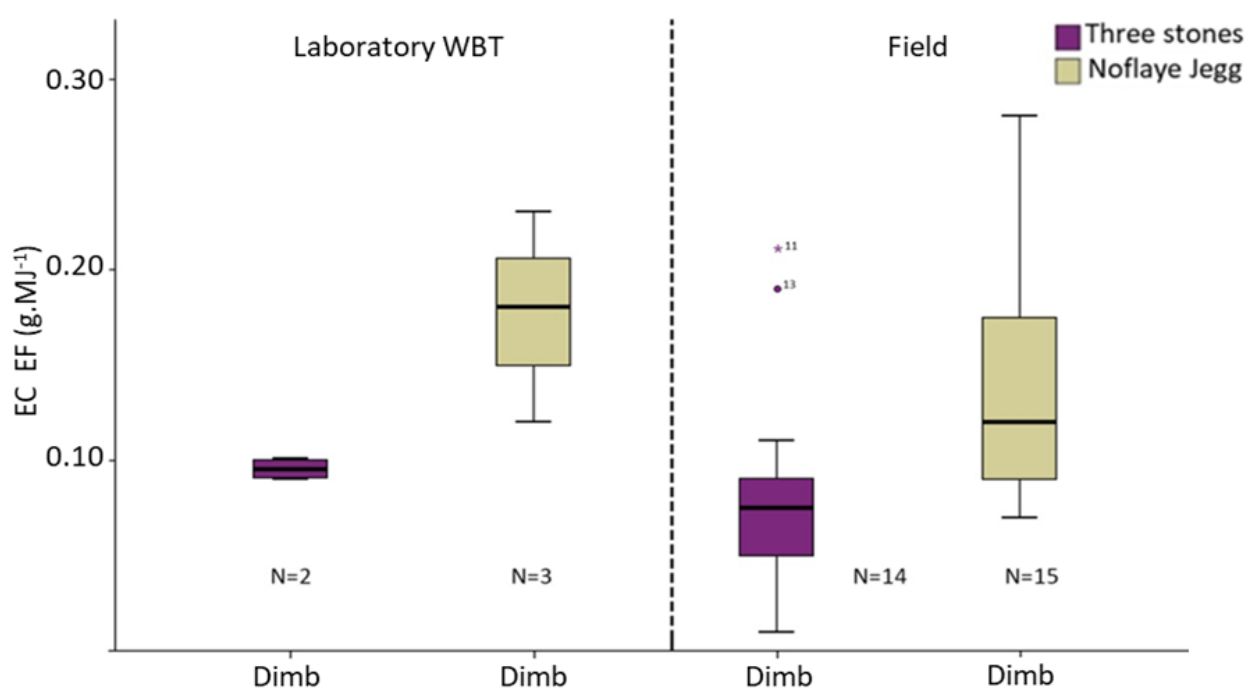

Fig. 4. Boxplot of EC EF ( $\left.\mathrm{g} \mathrm{MJ}^{-1}\right)$ for each type of stove and test.

not available, so total emissions have been estimated using two values of exfiltration rate from previous studies $(26 \%$ and 80\%) (Venkataraman et al., 2005 and Soneja et al., 2015, respectively). Annual EC and OC emissions per stove were then factored by the Global Warming Potential (GWP) value recommended by the IPCC, 900 for EC (Bond et al., 2013) and -46 for OC (Bond et al., 2011), for a time horizon of 100 years.

Fig. 5 presents the net climatic effect estimated with regard to $\mathrm{EC}$ and $\mathrm{OC}$ emissions for the three-stone fire and noflaye jegg (in tons of $\mathrm{CO}_{2}$-eq per year). At this point, it is important to highlight that a complete assessment of the global warming potential should include other species coemitted from residential cookstove use (Smith et al., 2000; Bhattacharya et al., 2002; Roden et al., 2006). Using the data of fuel consumption and emission factors obtained in this study, across a 100-year horizon, noflaye jegg showed an overall increase of $88 \%$ global warming potential in comparison to the traditional stove. In consequence, while the use of noflaye jegg has clear benefits for improving indoor air quality (Sota et al., 2014), our results suggest that this type of rocket stove, under typical cooking practices and fuelwood used in Senegal, may lead to negative climate effects with regard to carbonaceous aerosol emissions, although a complete analysis would include co-emitted species.

The fact that rocket and other types of natural draft stoves increase EC EFs is known (MacCarty et al., 2008; Arora and Jain, 2015). The unexpected point is that noflaye jegg stove did not provide fuel saving benefits, neither in our laboratory study, nor in the field. For this reason, our work emphasizes the importance of taking into account total EC and OC emissions in addition to EFs.

Besides this, total annual emissions of EC and OC from residential burning of fuelwood in Senegal were estimated using the average value of EC and OC EFs determined in this study (1.85 $\mathrm{g} \mathrm{EC} \mathrm{kg}^{-1}$ and $3.97 \mathrm{~g} \mathrm{OC} \mathrm{kg}^{-1}$ ) and the total annual firewood used in Senegalese households (450 ktoe year ${ }^{-1}$, for the period 2000-2005) (Dafrallah, 2009).
As previously discussed, EC and OC EFs vary significantly across different types of stove-fuel combinations. However, the average EFs from this study could be considered as representative of Senegal, as they were estimated from a set of biomass cookstoves and wood species widely used in the country. Fuel consumption is also highly dependent on type of stove used, but data on the fractions of different stoves used in Senegal are unavailable, so the total firewood annually used in the Senegalese households was the best information available.

Total emissions of EC and OC from residential fuelwood combustion in Senegal were estimated to be $421.1 \pm 213.0$ and $561.4 \pm 411.4 \mathrm{t} \mathrm{year}^{-1}$, respectively, with $26 \%$ of exfiltration rate, and $1295.6 \pm 655.3$ and $1727.5 \pm 1265.8$ t year $^{-1}$ with $80 \%$ of exfiltration rate. Factoring by $\mathrm{GWP}_{100}$ values, net effect of EC and OC emissions from household fuelwood consumption in Senegal were $353.1 \mathrm{kt}$ of $\mathrm{CO}_{2}$-eq with $26 \%$ of exfiltration rate and $1086.6 \mathrm{kt}$ of $\mathrm{CO}_{2}$-eq with $80 \%$ of exfiltration (Fig. 6).

Using the $5^{\text {th }}$ percentile of the EC and OC EF data set and $26 \%$ of exfiltration rate, the result was $173.4 \mathrm{kt}$ of $\mathrm{CO}_{2}$-eq, and, when using the $95^{\text {th }}$ percentile of EC and OC EFs and $80 \%$ of exfiltration rate, calculations show a result of $2031.9 \mathrm{kt}$ of $\mathrm{CO}_{2}$-eq. This range (173.4-2031.9 kt of $\mathrm{CO}_{2}$-eq) constitutes a rough estimation of the net effect on climate of carbonaceous aerosols emitted into the atmosphere from household use of fuelwood for cooking in Senegal.

It is important to highlight that a complete assessment of the global warming potential should include other species co-emitted from residential cookstove use (Smith et al., 2000; Bhattacharya et al., 2002; Roden et al., 2006). However, the objective at this stage was to assess the net climate effect of cooking-related carbonaceous aerosol emissions in Senegal, which is still uncertain.

\section{CONCLUSIONS}

This work provides original estimates of cooking-related 


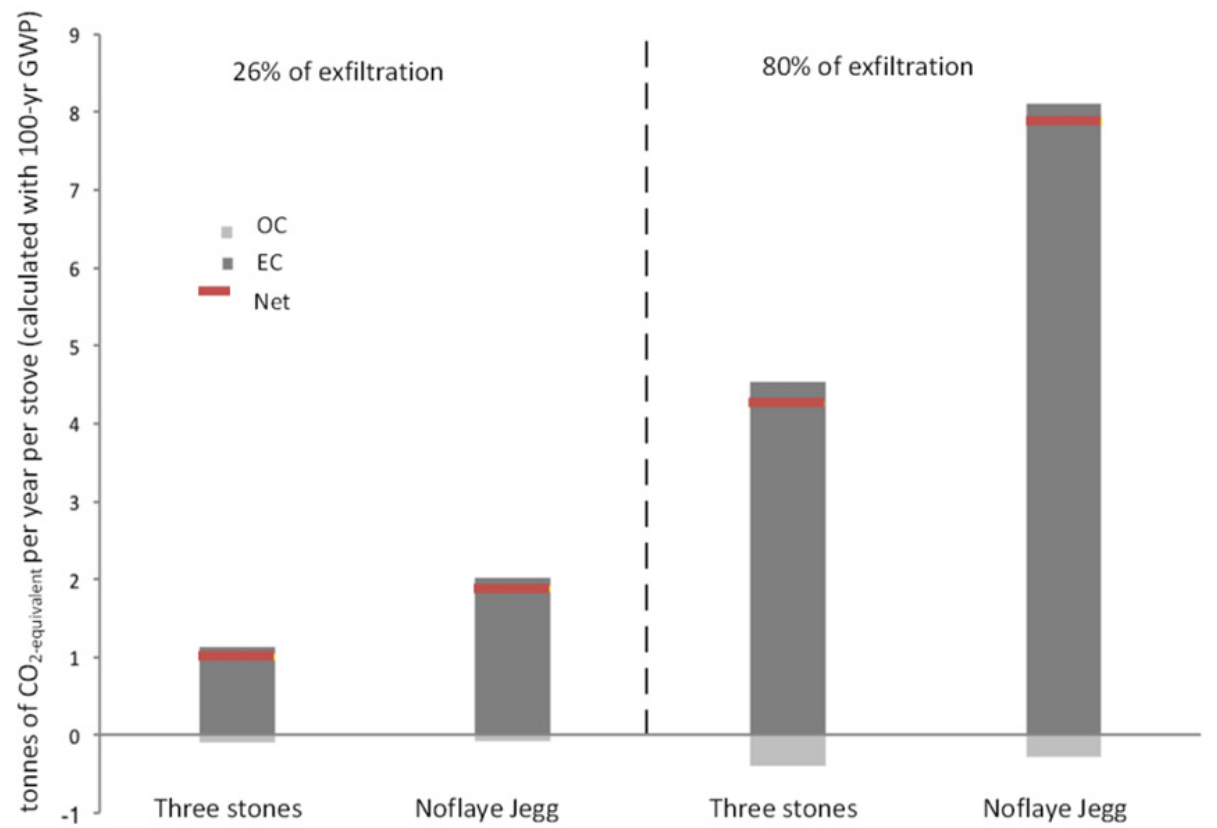

Fig. 5. Tonnes of $\mathrm{CO}_{2}$-equivalent per year per stove (calculated with 100-yr GWP) from EC and OC emitted during one year of use of noflaye jegg stove and three-stone fire. (Co-emitted species are not included in the analysis.)

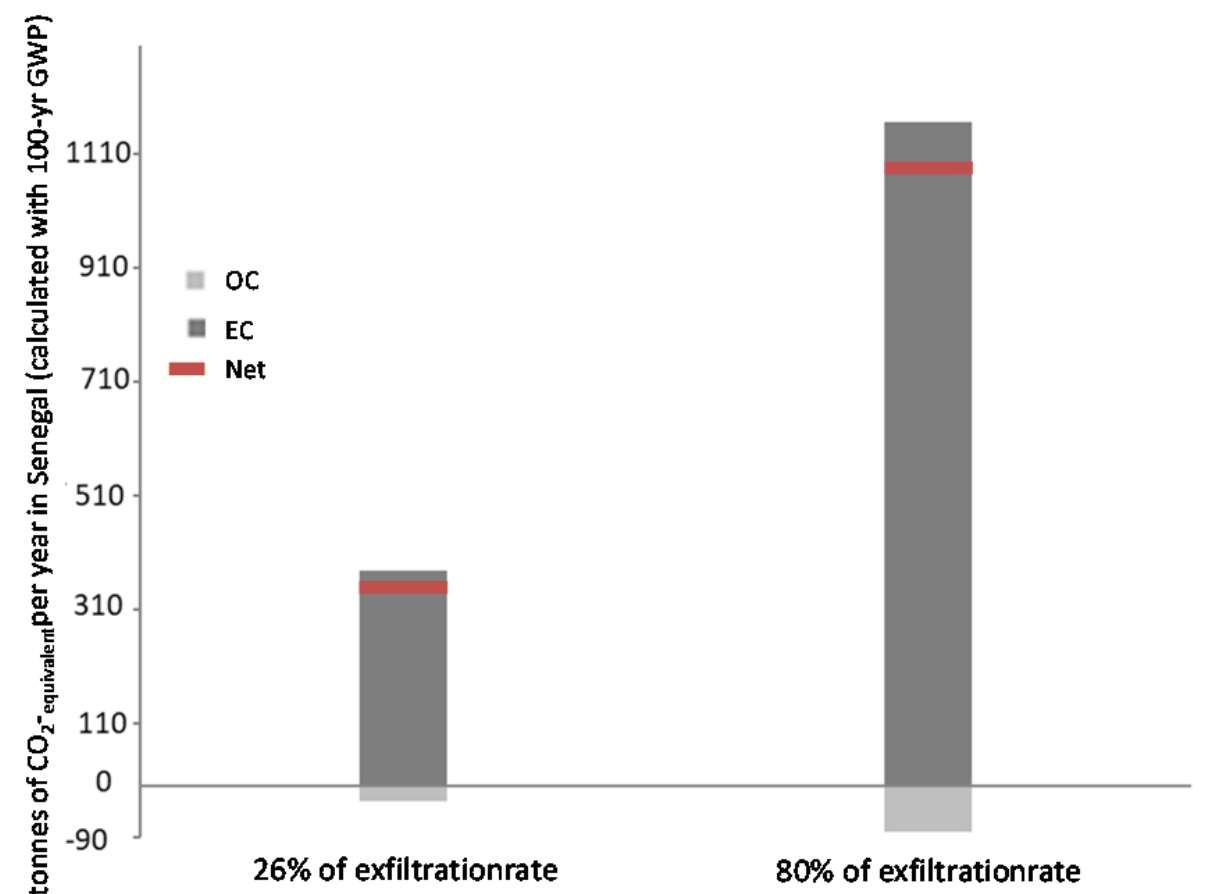

Fig. 6. Tonnes of $\mathrm{CO}_{2}$-equivalent per year in Senegal (calculated with 100-yr GWP) from EC and OC emitted from household fuelwood cookstoves, for an exfiltration rate of $26 \%$ and $80 \%$.

carbonaceous aerosol emissions in Senegal, where data were previously unavailable, thus contributing critical information that can be input into atmospheric models and supporting future mitigation strategies at national and regional levels.

However, uncertainties in the EF estimates as well as in the quantification of consumed fuel remain. Moreover, the 100-year GWP value for black carbon ranges from 120 to
1800 when all forcing mechanisms are included and can vary by about $\pm 30 \%$ by the region of emission (Henze et al., 2012; Myhre et al., 2013; Lacey and Henze, 2015).

Further laboratory and field studies should be performed in other regions of Senegal and West Africa with different stove-fuel combinations. The seasonality of carbonaceous emissions and the warming effect of brown carbon should also be studied. 
These studies should focus especially on biomass-based advanced technologies and fuels, such as gasifiers and pellets, as they will most likely be the most accessible and affordable clean cooking solutions in this region in the short to medium term. To the extent possible, EFs should be characterized in the field under real-world cooking conditions.

\section{ACKNOWLEDGEMENTS}

We would like to thank the families of Bibane, especially the women, for their kindness. This study has been financed by the Global Alliance for Clean Cookstoves, the Iberdrola Foundation and the Spanish National Research Council (CSIC, ICOOP programme through project COOPB20122). We thank the referees for their helpful comments.

\section{SUPPLEMENTARY MATERIAL}

Supplementary data associated with this article can be found in the online version at http://www.aaqr.org.

\section{REFERENCES}

Akagi, S.K., Yokelson, R.J., Wiedinmyer, C., Alvarado, M.J., Reid, J.S., Karl, T., Crounse, J.D. and Wennberg, P.O. (2011). Emission factors for open and domestic biomass burning for use in atmospheric models. Atmos. Chem. Phys. 11: 4039-4072.

Arora, P. and Jain, S. (2015). Estimation of organic and elemental carbon emitted from wood burning in traditional and improved cookstoves using controlled cooking test. Environ. Sci. Technol. 49: 3958-3965.

Atiku, F.A., Mitchell, E.J.S., Lea-Langton, A.R., Jones, J.M., Williams, A. and Bartle, K.D. (2016). The impact of fuel properties on the emissions from the combustion of biomass and other solid fuels in a fixed bed domestic stove. Fuel Process. Technol. 151: 117-125.

Bailis, R., Ogle, D., MacCarty, N. and Still, D. (2007). The Water Boiling Test (WBT). Household Energy and Health Programme Shell Foundation.

Bhattacharya, S.C., Albina, D.O. and Salam, P.A. (2002). Emission factors of wood and charcoal-red cookstoves. Biomass Bioenergy 23: 453-469.

Bond, T.C. (2004). A technology-based global inventory of black and organic carbon emissions from combustion. J. Geophys. Res. 109: D14203

Bond, T.C. and Bergstrom, R.W. (2006). Light absorption by carbonaceous particles: An investigative review. Aerosol Sci. Technol. 40: 27-67.

Bond, T.C., Bhardwaj, E., Dong, R., Jogani, R., Jung, S., Roden, C., Streets, D.G. and Trautmann, N.M. (2007). Historical emissions of black and organic carbon aerosol from energy-related combustion, 1850-2000. Global Biogeochem. Cycles 21: GB2018.

Bond, T.C., Zarzycki, C., Flanner, M.G. and Koch, D.M. (2011). Quantifying immediate radiative forcing by black carbon and organic matter with the Specific
Forcing Pulse. Atmos. Chem. Phys. 11: 1505-1525.

Bond, T.C., Doherty, S.J., Fahey, D.W., Forster, P.M., Berntsen, T., DeAngelo, B.J., Flanner, M.G., Ghan, S., Kärcher, B., Koch, D., Kinne, S., Kondo, Y., Quinn, P.K., Sarofim, M.C., Schultz, M.G., Schulz, M., Venkataraman, C., Zhang, H., Zhang, S., Bellouin, N., Guttikunda, S.K., Hopke, P.K., Jacobson, M.Z., Kaiser, J.W., Klimont, Z., Lohmann, U., Schwarz, J.P., Shindell, D., Storelvmo, T., Warren, S.G. and Zender, C.S. (2013). Bounding the role of black carbon in the climate system: A scientific assessment: BLACK CARBON IN THE CLIMATE SYSTEM. J. Geophys. Res. 118: 5380-5552.

Cachier, H., Liousse, C., Pertuisot, M.H., Gaudichet, A., Echalar, F. and Lacaux, J.P. (1996). African fire particulate emissions and atmospheric influence. In Biomass burning and global change, Levine J.S. (Ed.), MIT Press, Cambridge, Mass., pp. 428-440.

Cavalli, F., Viana, M., Yttri, K.E., Genberg, J. and Putaud, P. (2010). Toward a standardised thermal-optical protocol for measuring atmospheric organic and elemental carbon: The EUSAAR protocol. Atmos. Meas. Tech. 3: 79-89.

Chafe, Z.A., Brauer, M., Klimont, Z., Van Dingenen, R., Mehta, S., Rao, S., Riahi, K., Dentener, F. and Smith, K.R. (2014). Household cooking with solid fuels contributes to ambient $\mathrm{PM}_{2.5}$ air pollution and the burden of disease. Environ. Health Perspect. 122: 1314-1320.

Chen, Y., Sheng, G., Bi, X., Feng, Y., Mai, B. and Fu, J. (2005). Emission factors for carbonaceous particles and polycyclic aromatic hydrocarbons from residential coal combustion in China. Environ. Sci. Technol. 39: 18611867.

Chen, Y., Roden, C.A. and Bond, T.C. (2012). Characterizing biofuel combustion with patterns of realtime emission data (PaRTED). Environ. Sci. Technol. 46: 6110-6117.

Chomanee, J., Tekasakul, S., Tekasakul, P., Furuuchi, M. and Otani, Y. (2009). Effects of moisture content and burning period on concentration of smoke particles and particle-bound polycyclic aromatic hydrocarbons from rubber-wood combustion. Aerosol Air Qual. Res. 9: 404-411.

Chung, S.H. and Seinfeld, J.H. (2002). Global distribution and climate forcing of carbonaceous aerosols. $J$. Geophys. Res. 107: 4407.

Dafrallah, T. (2009). Energy security in west Africa the case of Senegal. Final report. Enda, Senegal.

de la Sota, C., Kane, M., Mazorra, J., Lumbreras, J., Youm, I. and Viana, M. (2017). Intercomparison of methods to estimate black carbon emissions from cookstoves. Sci. Total Environ. 595: 886-893.

EPA, PCIA, GACC (2014). The water boiling test. Version 4.2.3. Cookstove Emissions and Efficiency in a Controlled Laboratory Setting. U.S. Environmental Protection Agency, Partnership for Clean Indoor Air, Global Alliance for Clean Cookstoves.

Feng, Y., Ramanathan, V. and Kotamarthi, V.R. (2013). Brown carbon: A significant atmospheric absorber of solar radiation? Atmos. Chem. Phys. 13: 8607-8621.

Grieshop, A.P., Marshall, J.D. and Kandlikar, M. (2011). Health and climate benefits of cookstove replacement 
options. Energy Policy 39: 7530-7542.

Henze, D.K., Shindell, D.T., Akhtar, F., Spurr, R.J.D., Pinder, R.W., Loughlin, D., Kopacz, M., Singh, K. and Shim, C. (2012). Spatially refined aerosol direct radiative forcing efficiencies. Environ. Sci. Technol. 46: 9511-9518.

Jetter, J., Zhao, Y., Smith, K.R., Khan, B., Yelverton, T., DeCarlo, P. and Hays, M.D. (2012). Pollutant emissions and energy efficiency under controlled conditions for household biomass cookstoves and implications for metrics useful in setting international test standards. Environ. Sci. Technol. 46: 10827-10834.

Johnson, M., Edwards, R., AlatorreFrenk, C. and Masera, O. (2008). In-field greenhouse gas emissions from cookstoves in rural Mexican households. Atmos. Environ. 42: 1206-1222.

Lacey, F. and Henze, D. (2015). Global climate impacts of country-level primary carbonaceous aerosol from solidfuel cookstove emissions. Environ. Res. Lett. 10: 114003.

Lamarque, J.F., Bond, T.C., Eyring, V., Granier, C., Heil, A., Klimont, Z., Lee, D., Liousse, C., Mieville, A., Owen, B., Schultz, M.G., Shindell, D., Smith, S.J., Stehfest, E., Van Aardenne, J., Cooper, O.R., Kainuma, M., Mahowald, N., McConnell, J.R., Naik, V., Riahi, K. and van Vuuren, D.P. (2010). Historical (1850-2000) gridded anthropogenic and biomass burning emissions of reactive gases and aerosols: Methodology and application. Atmos. Chem. Phys. 10: 7017-7039.

Lee, C.M. and Chandler, C. (2013). Assessing the climate impacts of cookstove projects: Issues in emissions accounting. Chall. Sustainability 1: 53.

Li, X., Wang, S., Duan, L., Hao, J. and Nie, Y. (2009). Carbonaceous aerosol emissions from household biofuel combustion in China. Environ. Sci. Technol. 43: 60766081.

MacCarty, N., Ogle, D., Still, D., Bond, T., Roden, C. and Willson, B. (2007). Laboratory comparison of the global-warming potential of six categories of biomass cooking stoves. Aprovecho Research Center, Creswell, Oregon, USA.

MacCarty, N., Ogle, D., Still, D., Bond, T. and Roden, C. (2008). A laboratory comparison of the global warming impact of five major types of biomass cooking stoves. Energy Sustainable Dev. 12: 56-65.

MacCarty, N., Still, D. and Ogle, D. (2010). Fuel use and emissions performance of fifty cooking stoves in the laboratory and related benchmarks of performance. Energy Sustainable Dev. 14: 161-171.

Mahmood, A. (1993). Suitability of Casuarina equisetifolia wood for pulp and paper industry in Pakistan. Pak. J. Bot. 25: 179-182.

Mitchell, E.J.S., Lea-Langton, A.R., Jones, J.M., Williams, A., Layden, P. and Johnson, R. (2016). The impact of fuel properties on the emissions from the combustion of biomass and other solid fuels in a fixed bed domestic stove. Fuel Process. Technol. 142: 115-123.

Myhre, G., Shindell, D., Bréon, F.M., Collins, W., Fuglestvedt, J., Huang, J., Koch, D., Lamarque, J.F., Lee, D., Mendoza, B., Nakajima, T., Robock, A., Stephens, G.,
Takemura, T. and Zhang, H. (2013). Climate Change 2013: The physical science basis. Contribution of working Group I to the Fifth assessment report of the intergovernmental panel on climate change. Chapter 8 . Anthropogenic and Natural Radiative Forcing. Cambridge University Press, Cambridge, United Kingdom and New York, NY, USA.

Naeher, L.P., Leaderer, B.P. and Smith, K.R. (2000). Particulate matter and carbon monoxide in highland Guatemala: Indoor and outdoor levels from traditional and improved wood stoves and gas stoves. Indoor Air 10: 200-205.

Petzold, A., Ogren, J.A., Fiebig, M., Laj, P., Li, S.M., Baltensperger, U., Holzer-Popp, T., Kinne, S., Pappalardo, G., Sugimoto, N., Wehrli, C., Wiedensohler, A. and Zhang, X.Y. (2013). Recommendations for reporting "black carbon" measurements. Atmos. Chem. Phys. 13: 8365-8379.

Pokhrel, R.P., Wagner, N.L., Langridge, J.M., Lack, D.A., Jayarathne, T., Stone, E.A., Stockwell, C.E., Yokelson, R.J. and Murphy, S.M. (2016). Parameterization of single-scattering albedo (SSA) and absorption Ångström exponent (AAE) with EC/OC for aerosol emissions from biomass burning. Atmos. Chem. Phys. 16: 95499561.

Ramanathan, N., Lukac, M., Ahmed, T., Kar, A., Praveen, P.S., Honles, T., Leong, I., Rehman, I.H., Schauer, J.J. and Ramanathan, V. (2011). A cellphone based system for large-scale monitoring of black carbon. Atmos. Environ. 45: 4481-4487.

Ramanathan, V. and Carmichael, G. (2008). Global and regional climate changes due to black carbon. Nat. Geosci. 1: 221-227.

Rau, J.A. (1989). Composition and size distribution of residential wood smoke particles. Aerosol Sci. Technol. 10: 181-192.

Roden, C.A., Bond, T.C., Conway, S. and Pinel, A.B.O. (2006). Emission factors and real-time optical properties of particles emitted from traditional wood burning cookstoves. Environ. Sci. Technol. 40: 6750-6757.

Roden, C.A., Bond, T.C., Conway, S., OsortoPinel, A.B., MacCarty, N. and Still, D. (2009). Laboratory and field investigations of particulate and carbon monoxide emissions from traditional and improved cookstoves. Atmos. Environ. 43: 1170-1181.

Salako, G.O. (2012). Exploring the variation between EC and BC in a variety of locations. Aerosol Air Qual. Res. 12: $1-7$.

Samba, S.A.N. (2001). Effect of Cordylapinnata litter on crop yield: An experimental agroforestry approach. Ann. For. Sci. 58: 99-107.

Shen, G., Yang, Y., Wang, W., Tao, S., Zhu, C., Min, Y., Xue, M., Ding, J., Wang, B., Wang, R., Shen, H., Li, W., Wang, X. and Russell, A.G. (2010). Emission factors of particulate matter and elemental carbon for crop residues and coals burned in typical household stoves in China. Environ. Sci. Technol. 44: 7157-7162.

Shen, G., Wen, W., Yanyan, Z., Yujia, M., Bin, W., Rong, W., Wei, L., Huizhong, S., Ye, H., Yifeng, Y., Wei, W., 
Xilong, W., Xuejun, W. and Shu, T. (2012). Emission factors, size distributions, and emission inventories of carbonaceous particulate matter from residential wood combustion in rural China. Environ. Sci. Technol. 46: 4207-4214.

Shen, G., Tao, S., Wei, S., Chen, Y., Zhang, Y., Shen, H., Huang, Y., Zhu, D., Yuan, C., Wang, H., Wang, Y., Pei, L., Liao, Y., Duan, Y., Wang, B., Wang, R., Lv, Y., Li, W., Wang, X. and Zheng, X. (2013). Field measurement of emission factors of PM, EC, OC, parent, nitro-, and oxy- polycyclic aromatic hydrocarbons for residential briquette, coal cake, and wood in rural Shanxi, China. Environ. Sci. Technol. 47: 2998-3005.

Shoemaker, J.K., Schrag, D.P., Molina, M.J. and Ramanahatan, V. (2013). What role for short-lived climate pollutants in mitigation policy? Science 342: 132-132.

Smith, K.R., Uma, R., Kishore, V.V.N., Lata, K., Joshi, V., Zhang, J.J., Rasmussen, R.A. and Khalil, M.A.K. (2000). Greenhouse gases from small-scale combustion devices in developing countries (No. EPA-600/R-00-052), Research and Development. United States Environmental Protect ion Agency, Washington, DC, USA.

Soneja, S.I., Tielsch, J.M., Curriero, F.C., Zaitchik, B., Khatry, S.K., Yan, B., Chillrud, S.N. and Breysse, P.N. (2015). Determining particulate matter and black carbon exfiltration estimates for traditional cookstove use in rural Nepalese village households. Environ. Sci. Technol. 49: 5555-5562.

Sota, C. de la, Lumbreras, J., Mazorra, J., Narros, A., Fernández, L. and Borge, R. (2014). Effectiveness of improved cookstoves to reduce indoor air pollution in developing countries. The case of the cassamance natural subregion, Western Africa. J. Geosci. Environ. Prot. 2: 1-5.

The World Bank (2013). Global tracking framework. Sustainable Energy for All (SEforALL). The World
Bank, Washington, DC, USA.

Tillman, D.A. (1987). Wood as an energy resource. Academic Press, New York, USA.

Turpin, B.J., Saxena, P. and Andrews, E. (2000). Measuring and simulating particulate organics in the atmosphere: Problems and prospects. Atmos. Environ. 34: 2983-3013.

Venkataraman, C. and Rao, G.U.M. (2001). Emission factors of carbon monoxide and size-resolved aerosols from biofuel combustion. Environ. Sci. Technol. 35: 2100-2107.

Venkataraman, C., Habib, G., Eiguren-Fernandez, A., Miguel, A.H. and Friedlander, S.K. (2005). Residential biofuels in South Asia: Carbonaceous aerosol emissions and climate impacts. Science 307: 1454-1456.

Wang, Y., Sohn, M.D., Wang, Y., Lask, K.M., Kirchstetter, T.W. and Gadgil, A.J. (2014). How many replicate tests are needed to test cookstove performance and emissions? Three is not always adequate. Energy Sustainable Dev. 20: 21-29.

Wathore, R., Mortimer, K. and Grieshop, A.P. (2017). Inuse emissions and estimated impacts of traditional, natural- and forced-draft cookstoves in rural Malawi. Environ. Sci. Technol. 51: 1929-1938.

WHO (2009). Country profile of environmental burden of disease. Senegal. World Health Organization, Geneva, Switzerland.

Zhang, J., Smith, K.R., Ma, Y., Ye, S., Jiang, F., Qi, W., Liu, P., Khalil, M.A.K., Rasmussen, R.A. and Thorneloe, S.A. (2000). Greenhouse gases and other airborne pollutants from household stoves in China: A database for emission factors. Atmos. Environ. 34: 4537-4549.

Received for review, February 16, 2018 Revised, September 10, 2018 Accepted, September 17, 2018 